\title{
Violências nas escolas: \\ uma rotina normativa
}

Violence in schools:

a prescriptive routine

\section{Violencias en las escuelas:}

una rutina normativa

MARCOS ANTÔNIO PAZ SILVEIRA*

Instituto Federal do Amazonas, Coari- AM, Brasil.

\begin{abstract}
ANTÔNIO CARLOS DO NASCIMENTO OSÓRIO**
Universidade Federal do Mato Grosso do Sul, Campo Grande- MS, Brasil.
\end{abstract}

\begin{abstract}
RESUMO: Nas escolas públicas ou privadas, em municípios de grande ou pequena densidade populacional, independentemente das condições econômicas, sociais e culturais, existem questões pertinentes às violências, pauta de discussões nas práticas pedagógicas. O objetivo é analisar ações e processos discursivos decorrentes de violências, a partir do olhar dos trabalhadores em educação e compreender como a escola tem determinado novas e expressivas configurações de violências em sua rotina para a justificação social.
\end{abstract}

Palavras-chave: Violências. Discursos normativos. Escolas.

\begin{abstract}
In public or private schools, in municipalities of great or small population density, regardless of the economic, social and cultural conditions, there are relevant issues related to violence, a subject of discussions in pedagogical practices. The aim is to analyze discursive actions and processes resulting from violence, from the
\end{abstract}

* Doutor e Mestre em Educação pela Universidade Federal de Mato Grosso do Sul. É graduado em Educação Física, com especialização em Fisiologia do Exercício. Atualmente é professor do Instituto Federal do Amazonas. E-mail: <marcospaz.psb@gmail.com>.

* Professor dos Programas de Pós-Graduação em Educaçãoe Psicologia da Universidade Federal de Mato Grosso do Sul. Coordenador dos Grupos de Estudos/CNPq: Grupo de Estudo e Investigações Acadêmicas nos Referenciais Foucaultianos (GEIARF) e Educação, Trabalho e Formação Profissional. E-mail: <antonio.osorio@ufms.br>. 
perspective of the educational workers and to understand how school has determined new and expressive configurations of violence in its routine for social justification.

Keywords: Violence. Normative speeches. Schools.

RESUMEN: En las escuelas públicas o privadas, en municipios de gran o pequeña densidad poblacional, independientemente de las condiciones económicas, sociales y culturales, existen cuestiones pertinentes a las violencias, pauta de discusiones en las prácticas pedagógicas. El objetivo es analizar acciones y procesos discursivos derivados de violencias a partir de la mirada de los trabajadores en educación, y comprender cómo la escuela ha determinado nuevas y expresivas configuraciones de violencias en su rutina para la justificación social.

Palabras clave: Violencias. Discursos normativos. Escuelas.

\section{Introdução}

A

o localizar a violência escolar como tema deste artigo, muitas questões afloram, perturbam e acompanham o trajeto investigativo, e ainda estão presentes.

Dúvidas, medos e receios ganham corpo, pois se fala sobre a violência escolar, mas não se explicita porque ela existe. Ao tentar fazer esse exercício, a dúvida que surgiu foi a de como constituir uma unidade do tema/objeto se ele é marcado por aspectos policêntricos, inseridos em redes de relações, com muitos centros de produção, diferenciação e origens e, ao mesmo tempo, por várias divisões.

Esse tipo de violência não tem uma identidade específica, pois sua multiplicidade de ações e composição discursiva, a partir do olhar dos trabalhadores em educação, sob o prisma da rotina escolar, constrói uma mecânica de poder e saber que consolida esse espaço como instituição social fabricante de comportamentos, atestados pelo estabelecimento dos desvios das normas e legitimados pelas verdades sobre violências.

A proposta investigativa é subsidiada através da aplicação de inventários de pesquisa, que deve ser compreendido como um dos processos necessários, em que são explicitadas e sinalizadas as condições operativas das pretensões da coleta executada em parceria com a Federação dos Trabalhadores em Educação do Mato Grosso do Sul (Fetems). Essa coleta de dados realizada em parceria com a Fetems inventariou 891 trabalhadores em educação, distribuídos em todos os municípios do estado de Mato Grosso do Sul, reforçando a especificidade do lócus da pesquisa. 
A expressão inventário é originalmente empregada em teorias aplicadas aos campos do direito, da economia e das ciências contábeis, tendo um caráter técnico em que cada área segue regras próprias com vistas aos seus propósitos. Dessa forma, conquanto semelhantes entre si, as finalidades variam. Diante dessas questões, o objetivo é analisar ações e processos discursivos decorrentes de violências que se encontram distribuídos nos entremeios pedagógicos, a partir do olhar dos trabalhadores em educação, na possibilidade de demonstrar outro olhar para o enfrentamento da violência na escola.

Com base no referencial foucaultiano, a composição do discurso das violências é iniciada por uma trajetória de contradições para construção de olhar que sinalize o enfrentamento dessa temática na escola. As análises desses dados são efetuadas numa incursão pelo aspecto disciplinar voltado às questões de poder e norma, produzindo saberes que compõem uma identificação do que pode ser as violências na escola, a partir da prática discursiva dos trabalhadores em educação.

\section{Poder, normalização e violências}

Na teorização foucaultiana, a questão do poder e as diferentes formas desse exercício, a disciplina e suas tecnologias de poder constroem edifícios constituídos pelas práticas culturais, que dão sustentabilidade às noções de poder nas relações entre indivíduos e grupos sociais, como formas de produção de saberes.

O poder é abordado como um jogo de forças permanente e não localizável, no sentido de coisa concreta, de não pertencimento a algo ou alguém. Foucault (2002) faz uma incursão pelos mecanismos de poder, discute os efeitos, relações e dispositivos que o permeiam e como o poder transita na sociedade. Em suas abordagens, Foucault (2002, p. 22) conduz à seguinte ponderação:

[...] se o poder é mesmo, em si, emprego e manifestação de uma relação de força, em vez de analisá-lo em termos de cessão, contrato, alienação, em vez mesmo de analisá-lo em termos funcionais de recondução das relações de produção, não se deve analisá-lo antes e acima de tudo em termos de combate, de enfrentamento ou de guerra? [...] o poder é a guerra, é a guerra continuada por outros meios.

O significado expresso a partir dessas análises das relações de poder em funcionamento na sociedade está relacionado à força e ao poder político, função de manutenção desse processo através da política, que é a guerra continuada por outros meios. As relações de poder se configuram por meio de modos de ação coletivos, mas que têm na utilidade individual - o micropoder - a ferramenta mais utilitária. Para essa eficiência, a percepção de liberdade social funciona como linimento a todo mecanismo dessa complexa engrenagem de poder. Na afirmativa de Foucault (2002), o poder só se exerce plenamente sobre sujeitos livres. Poder e liberdade não são elementos antagônicos, em 
que a ascensão de um submerge o outro e nessa configuração social leva às conceituações dissonantes.

Na teorização foucaultiana essa simbiose é relatada como essencial para uma sociedade se aproximar da concretude. O poder decorre de práticas ou discursos específicos que se consolidam ou se desestabilizam. Essa operação não se vincula ao aspecto estritamente negativo de poder, que, historicamente somos levados a sentir, na expressividade da palavra, na perspectiva de estado e dominação de classes; é um poder que produz positividade e verdades.

Poder, para Foucault, é apenas a forma, variável e instável, do jogo de forças que definem as relações sociais em cada momento histórico concreto, e que se define através de práticas e discursos específicos. Só se pode apreender o tipo de poder em jogo em um determinado campo de práticas e discursos - local e temporalmente delimitados - através de descrição minuciosa, em detalhes, do funcionamento dessas práticas, nunca pela aplicação de uma teoria geral do poder 'apriorística' (PASSOS, 2008, p. 11, grifo do autor).

Essa mecânica de poder não oferece à sociedade capitalista bases na força do poder político ou econômico que controlam os sujeitos; caracteriza uma mecânica de poder que deriva de uma tecnologia humana ao estado, como meio de sua própria sobrevivência, reelaborações por microrrelações de poder, criando arcabouços normativos para a população, aproximando o que denominam sociedade civil.

Observar a construção dessas relações de poder e consigná-las a um movimento histórico, à trajetória de configurações da violência, elabora instrumentos que compõem uma identidade epistemológica que se quer analisar. Nesse sentido, a arqueologia explicitada na teorização foucaultiana é o instrumento metodológico que possibilita descrever essas relações em diferentes séries, descontinuamente, mostrando rupturas e oscilações na construção dessa história.

Esse trabalho arqueológico possibilita a aproximação de um entendimento com as relações de poder e a produção dos discursos das violências que transitam no espaço escolar, conforme explicitado por Araújo (2001, p. 55): “Focaliza as práticas discursivas que formam o saber de uma época, os arquivos, isto é, os enunciados efetivamente ditos e o funcionamento dos discursos". Abre-se outro olhar nessa construção histórica, não de negação do que está posto, mas de outras perspectivas de verdades historicizadas, como descreve Navarro-Barbosa (2004, p. 103):

O relativismo histórico que emerge das análises sobre as condições de possibilidade e de emergência dos saberes leva à conclusão de que não há verdade para ser buscada nas diversas etapas constitutivas do saber, mas sim discursos historicamente detectáveis, que constroem verdades e possibilitam o exercício do poder.

É o discurso que deve ser analisado e compreendido. A composição do discurso vai dar subsídios para a amplitude da construção de verdades, significação das coisas e 
para compreensão de que se exerce o poder à medida que se entendem os acontecimentos discursivos. Busca-se, na raiz dos discursos, a suspensão do dito e não dito, as noções e unidades de continuidades que dão sentido aos acontecimentos discursivos em uma materialidade histórica que tem efeito e lugar.

Para Foucault (2003, p. 19), três grandes sistemas de exclusão atingem o discurso, "[...] a palavra proibida, a segregação da loucura e a vontade de verdade". Contudo, o autor aborda mais incisivamente a vontade de verdade, pois é nesse ponto que a maquinaria de relações de poder tem sua plena fecundidade.

A conformidade disciplinar do discurso acaba por ser imposto pela necessidade de legitimação de sua prática, ou seja, o regramento de sua composição discursiva é o que identifica em um determinado espaço. Tratando o discurso como uma prática discursiva majoritária no campo da educação, é o processo pedagógico que precisa dar conta e ter sentido transformador na vida das pessoas, especialmente de crianças e jovens frequentadores das escolas e da própria demanda contemporânea da educação em ser a escola uma instituição socialmente útil. No processo pedagógico cabe investigar a dinâmica escolar com relação às violências, não como fenômeno novo, mas como uma ação que transita na composição discursiva distribuída nos entremeios da educação.

\section{Inventários: dos dados coletados}

A coleta de dados realizada obteve inventários respondidos por trabalhadores em educação das redes pública estadual e municipal distribuída em todos os municípios de Mato Grosso do Sul. Essa representatividade traz significativa qualidade na coleta de dados. O inventário dividia-se em três partes: a primeira de identificação do informante, a segunda de coleta de informações gerais sobre a temática do inventário e a terceira parte, de perguntas com respostas "abertas" ao assunto.

Os dados obtidos nos inventários devolvidos revelaram que $78 \%$ dos participantes são do sexo feminino e 65\% pertencem à faixa etária compreendida entre 41 e 50 anos. Do universo apresentado nos inventários, $74 \%$ dos profissionais têm vínculo com a rede pública estadual. Os 26\% dos outros informantes estão ligados à rede pública municipal ou atuam em ambas as redes.

Outro ponto abordado na primeira parte do inventário relata o tempo de serviço na educação, que a pesquisa separou em magistério e setor administrativo. Identificou-se que parcela significativa, cerca de $54 \%$ do total coletado, tem 15 anos ou mais de atuação no magistério e dos que estão no setor administrativo, o percentual mais expressivo compreende trabalhadores de 5 até 15 anos de serviço. Desses, 76\% são trabalhadores em educação na condição de efetivos. 
Relativamente à formação acadêmica, as informações revelam que os trabalhadores em educação possuem graduação na ordem de 85\% do total coletado; $60 \%$ possuem especialização lato sensu e quase $7 \%$ possuem especialização stricto sensu, concluída ou em fase de conclusão, na proporção numérica de 51 em nível de mestrado e 9 de doutorado. Todos esses dados identificam o perfil e dão mostra do elevado percentual formativo dos entrevistados, do grau de instrução formal que corrobora a capacidade intelectual e crítica desse campo educacional.

Na segunda parte do inventário aplicado, estão as informações gerais com relação à temática "violência escolar", abordagem investigativa que a maioria dos entrevistados, aproximadamente $87 \%$, considerou importante, haja vista que $76 \%$ desses informantes afirmaram que nas escolas onde atuam há ocorrência de violências.

Relativamente à questão sobre com quem a violência tem ocorrido, dentre as várias alternativas de respostas destacou-se a ocorrência de violência entre alunos (aproximadamente $75 \%$ das respostas), seguido da violência entre alunos e professores (20\%) e da violência entre alunos e seus familiares em $15 \%$ dos casos.

Esses dados refletem não só o tipo de convívio no espaço escolar, mas uma estrutura social que funciona na centralidade de um tipo específico de conduta padrão que é a normalização dos seus indivíduos e, ainda, dá a conferir que, verdadeiramente, essas são as ocorrências já conhecidas. Subentende-se que, no âmbito escolar, o respeito e a boa conduta devam ser fundamentos essenciais para a escola, todavia, essa homogeneização de convívio não tem sido tarefa exitosa, o que pode ser reflexo da própria distribuição de direitos e deveres prescritos nos regimentos. Ratto (1997, p. 145) pondera o seguinte:

\footnotetext{
[...] fica especificado no regimento escolar um conjunto de comportamentos sob a forma de deveres das crianças e outro de proibições, entendendo-se que as últimas são mais categóricas do que os primeiros, embora estes também abram o campo de constituição do comportamento indisciplinado por parte do alunado. Assim, ficam estabelecidos deveres com relação a pontualidade, assiduidade, respeito para com todos os sujeitos da escola, responsabilidades quanto à conservação das instalações escolares e o dever de cumprir as tarefas definidas pelas autoridades escolares, dentre outros. Já o leque de prescrições relativo às proibições aponta, a princípio, para o que está vedado incondicionalmente ao alunado, como, por exemplo, agredir física ou verbalmente as pessoas.
}

Observa-se, pela análise das questões, que a maior parte dos acontecimentos ligados a atitudes de violência é ocasionada entre alunos. Essa medida é parte da visão constituinte do aparato disciplinar que todos os agentes envolvidos na escola tendem a estabelecer como parâmetro, pois a delimitação do que vem a ser agressão também traz implícita a multiplicidade conceitual, paralelamente às violências; trata-se de um disciplinamento colocado para todos como parte essencial da convivência e que depende da inter-relação normativa produzida na escola. A escola constrói a prática discursiva 
de responsabilização do processo pedagógico e ramifica seus mecanismos de disciplina que envolvem, inclusive, a família.

É na família que a discursividade das violências está se justificando como proeminente das operações que ocorrem na rotina escolar e que a disciplina não se apresenta como instituição específica; ela é uma tecnologia presente em toda a sociedade, a escola apenas reforça ou reorganiza suas medidas controladoras para também responsabilizar essa função da família.

Esse disciplinamento não se estabelece somente no interior da escola, é parte constituinte de nossa sociedade, que se decompõe em diversas fontes normativas e faz com que todos os indivíduos sejam operadores e operados de um sistema de utilidade social; aquele que não produz socialmente passa para a anormalidade, quem não se encaixa nos padrões escolares em parte produz os comportamentos agressivos, será culpabilizado e sua família responsabilizada.

O momento em que ocorre a incidência da violência escolar, destacado como expressivo, é na saída da escola, em $47 \%$ dos relatos, e durante o recreio, com aproximadamente $43 \%$ de citações. Esses dados, conjugados à faixa etária dos alunos envolvidos nessas violências, revelam um destaque para alunos dos 11 aos 16 anos; em quase 87\% dos casos citados nos inventários a idade referência compreende essa faixa etária. Essa visão está atrelada à normalização da rotina escolar, em que seu desvio incide em ocorrências de indisciplina ou violência.

Uma situação captada nos inventários refere-se aos tipos de violência mais frequentes, observados pelos profissionais em educação participantes da coleta. Esses tipos de violência foram sugeridos no inventário, o participante poderia assinalar mais de uma alternativa. As respostas apontam: desrespeito aos colegas, quase $80 \%$ do total das respostas; xingamentos e agressões verbais, em 58\%; agressões físicas, com 54\%; desrespeito aos professores, $52 \%$ das respostas; constrangimento de pessoas com apelidos, coisas negativas sobre o jeito de "ser" ou do "corpo", em 50\%; deixar de fazer atividades solicitadas, em $46 \%$ das respostas. A alternativa danificação do prédio escolar, depredação do ambiente escolar e danificação dos materiais da escola, como mobiliários e equipamentos de informática, foi apontada em $27 \%$ das respostas.

Essa realidade escolar é demonstrada em diversas reclamações por parte da comunidade escolar e provoca, no cotidiano da escola, uma complexidade de ações que exploram capacidades a fim de que os conflitos de ordem comportamental sejam superados.

Outra questão constante no inventário refere-se à visão sobre a influência da mídia em relação às situações de violência na escola; o percentual de respostas afirmativas foi de $80 \%$ do total. Esses discursos e ações que reproduzem as ameaças ou ofensas, em exercícios de violentação iminente ao outro, todas de ordem comportamental, nas entrelinhas das práticas disciplinadoras se relaciona diretamente ao modo de como é percebida socialmente a violência. Há um número significativo de sujeitos que configuram uma 
realidade muitas vezes perceptível à rotina da escola, evidenciado por práticas de exclusão ou segregação, tanto na condição de agressores como na de agredidos, permanecendo um quadro de violentação geral com poucas ações produtivas - constata-se, mas não se modifica a ação no interior da escola, como será descrito adiante nas análises do que se tem feito para enfrentar as violências.

Relativamente à questão que pretendia identificar alunos participantes em situações de violências ou de uso de drogas, 53\% responderam que têm conhecimento de aluno alvo de Bullying e $47 \%$ assinalaram ter conhecimento de aluno que pratica Bullying contra outro colega. Esses dados são significativos, contudo se seguidos de outros dados como: $41 \%$ dos informantes apontaram ter conhecimento de alunos usuários de drogas lícitas (cigarros e álcool), 39\% conhecem aluno que feriu a integridade física de outro colega e 35\% identificam alunos usuários de drogas ilícitas (maconha, cocaína, cola, crack). Outras alternativas presentes no inventário tiveram um quantitativo menos expressivo no total das respostas.

Esse elevado índice de ocorrências de violências no ambiente escolar, provocado, principalmente, por parte de alunos usuários de drogas lícitas e ilícitas, conforme afirmativa dos entrevistados, demonstra a necessidade de novas ações por parte do poder público para dar condições de enfrentamento ao uso de drogas que acarreta violências na escola, como, por exemplo, a efetividade da legislação que visa, justamente, ao combate dessas ocorrências.

Com relação aos instrumentos que a escola utiliza para resolver as ocorrências de violência, havia 13 alternativas de respostas no inventário, com a possibilidade de escolha de mais de uma alternativa. Três delas foram as mais citadas: $65 \%$ das respostas apontam que a escola possui ficha de ocorrência e o envolvido é chamado para resolver a ocorrência; $59 \%$ responderam que, quando há reincidência, a família é convocada a tomar providências rigorosas e $54 \%$ responderam que a ocorrência é encaminhada ao Conselho Tutelar. O preenchimento de formulário específico para registro dos casos de violência foi citado em $22 \%$ das respostas, seguido por $20 \%$ em que a ocorrência é registrada na delegacia de polícia e 18\% em que as ocorrências são encaminhadas à Promotoria Pública.

Nos mecanismos disciplinares adotados na escola, a equidade na ação e reação dos deveres associados às penalidades é desproporcional, visto que grande parte das respostas analisadas é da ordem de que a escola registra e toma providências, mas a reincidência é significativa em relação a desvios ou não cumprimento da observância do regimento escolar com suas respectivas normas. O reflexo é que a escola não tem conseguido normalizar um comportamento padrão, desejo incutido na dinâmica pedagógica pelo poder disciplinar; na composição social contemporânea torna-se conflituosa a relação de convivência no espaço escolar.

Em outra questão da pesquisa, $74 \%$ dos trabalhadores em educação responderam que a escola em que atuam já acionou o Conselho Tutelar para resolver problema de 
aluno que praticou violência. Desse percentual, metade afirmou que a escola acionou o Conselho Tutelar diversas vezes, seguido por $42 \%$ que afirmam que às vezes o Conselho é acionado. Percebe-se, pelos dados coletados, que a prática escolar de acionar o Conselho Tutelar para resolver questões de violências no cotidiano escolar é bastante frequente, ou seja, é expressiva a atuação de instituição extraescolar na condução de práticas disciplinadoras voltadas às violências.

Por fim, há uma questão, nos inventários, que indaga se a escola já acionou a polícia para resolver questão de aluno que praticou violência. Pelas respostas, $61 \%$ dos informantes afirmaram que "sim"; desse percentual, 51\% afirmaram que a polícia é acionada, às vezes, e 33\% responderam que a polícia é acionada diversas vezes, ou seja, de acordo com esses dados, acionar a polícia é ação corriqueira no ambiente escolar e reforça o posicionamento de que a escola tem procurado resolver suas situações de conflitos com a ação de outras instituições sociais.

A terceira parte do inventário consistiu de perguntas passíveis de respostas "abertas". Vale destacar que os percentuais são das respostas afirmativas e, por se tratar de questões abertas, a resposta consta ou se enquadra em mais de um item tabulado, o que transcende o universo da totalidade, estipulado em 100\%.

Uma questão pergunta qual a principal causa da violência escolar. As respostas, dentre outras opiniões, revelam, majoritariamente, que a família desagregada e/ou desestruturada, aliada à falta de educação familiar, pode ser a principal causa. Esse posicionamento aparece em metade dos formulários respondidos, seguido da falta de acompanhamento e/ou família ausente da escola ( $24 \%$ das respostas), 18\% registram a falta de limites e/ou respeito às pessoas e 13\%, o excesso de liberdade e/ou ociosidade dos jovens.

Um aspecto relevante, nesse sentido, é que a escola sente o desligamento de uma cultura educacional por parte daqueles responsáveis por uma parcela na formação de crianças e jovens, seu núcleo familiar. A desagregação e/ou desestrutura a que se referem os trabalhadores em educação estão voltados para a capacidade que os núcleos familiares têm de edificar conceitos sociais e educacionais voltados à civilidade. A escola passa grande parte de seu tempo nesse conflito educacional e o reflexo é o distanciamento cada vez maior da educação formal para a adoção de medidas específicas que tentem dar respostas ao enquadramento formal de disciplinamento que a sociedade justifica como modelo de êxito social.

Nas escolas coexistem tipos de condutas disciplinares que se baseiam numa lógica de funcionamento; se as prerrogativas normativas são ameaçadas, proporcionalmente são estabelecidas medidas de repreensão para a manutenção da ordem. Isso justifica o grande percentual descrito anteriormente sobre o chamamento exaustivo de pais e/ou responsáveis à escola, do acionamento de outras instituições como o Conselho Tutelar, a Polícia Militar e o Ministério Público à escola, na tentativa de resolver questões de ordem disciplinar. 
Outra questão trata da ação mais eficiente para o enfrentamento da violência escolar. A alternativa mais abordada foi a de trazer a família para maior participação na escola e na vida escolar, em 31\% dos inventários, seguindo-se a alternativa de maior sensibilização e conscientização de alunos e pais, com 23\%. A promoção do diálogo/conversas na comunidade escolar foi escolhida por $23 \%$ dos informantes; o estabelecimento de disciplina e limites aos alunos cumprindo leis e regras escolares e penalizando os infratores obteve 18\% de respostas; promoção de palestras, projetos e cursos de combate à violência escolar teve $16 \%$ de escolhas e conscientização e união da comunidade escolar para esse enfrentamento está marcada em 13\% das respostas. Várias alternativas, em menor proporção, foram apresentadas nas respostas como ação para enfrentamento da violência escolar.

\section{Considerações finais}

Ao observar os discursos e os procedimentos de âmbito social no espaço escolar, constatou-se que a violência escolar deve ser considerada a partir de sua pluralidade, diante da definição epistemológica, e por diversas atitudes no espaço da escola. Por apresentar variáveis intervenientes, o relacionamento disciplinar situa-se entre um poder aplicável e um sistema educacional intencionalizado; as práticas discursivas sobre as violências são influenciadas por relações de saber e poder, características de nossa sociedade, tão bem reproduzidas na escola.

Diante dos dados e das respectivas análises, o disciplinamento escolar é preponderante no discurso de enfrentamento às violências na escola e muitos trabalhadores em educação, conforme os dados apresentados, afirmam claramente que os principais agentes causadores da incidência de relações de violências têm origem nos alunos e que a relação social não se separa do vínculo escolar.

Observou-se que há necessidade de fortalecer o aspecto didático-pedagógico e de procurar outras formas de condução na convivência escolar em que o conhecimento seja centro e objetivo nas ações nesse ambiente social, a fim de promover uma situação positiva de enfrentamento das violências, pois o processo educacional nas escolas, com base nos dados coletados, e a convivência escolar sofrem influências de relações verbais, físicas e psicológicas, que originam vários processos discursivos e transitam para a ação, apresentando-se na forma de violências.

Parece evidente que a interferência de fatores externos tem se misturado com a rotina no interior da escola, como o uso e tráfico de drogas, o uso de armas, gangues e outras relações de violências, mas é preciso desconstruir a sensação de que a escola está em processo de ebulição devido a essas interferências, uma vez que, pelos dados recolhidos na 
pesquisa, fica destacado que a maior incidência de violências nas escolas diz respeito às questões de relação interpessoal inerentes à composição de nossa sociedade.

Ficou especificado, também, que a convivência entre os próprios alunos, alunos e professores, alunos e demais trabalhadores em educação são relações que originam quase a totalidade das incidências das violências na escola. Conflitos que a escola normalizou nos indivíduos tão eficientemente, padronizando essa dinâmica comportamental por um bom tempo, e os justificou como um dos instrumentos de controle de massa, tornando-se um dos pilares da sociedade moderna.

É quase consenso entre os informantes que o envolvimento de toda a comunidade escolar - trabalhadores em educação, alunos, pais e responsáveis - em projetos voltados ao combate das violências, drogas e Bullying produz maiores chances de sucesso. Assim, na visão de todos, é fundamental a participação em ações que orientem o trabalho pedagógico na escola; também é notória, nas respostas dos trabalhadores em educação, a responsabilidade da família na disseminação de valores sociais aos jovens e para que o processo educacional tenha sucesso. Paralelamente a essa constatação, um grande percentual de respostas nos inventários direcionou, como sugestão para o enfrentamento das violências na escola, para um maior diálogo entre os atores envolvidos, maior participação da comunidade escolar, desenvolvimento de projetos e atividades voltadas à conscientização do convívio social e ao estímulo de preceitos de cidadania.

Pelos dados apresentados, pode-se afirmar que as violências, com suas nuances, são produções interligadas às ações que estão presentes em nossa sociedade e aos conflitos peculiares à rotina escolar oriundos de ressignificações de normas e relações de poder nos entremeios pedagógicos que padronizam conceitos e legitimam verdades sobre o discurso das violências nas escolas, acompanhando, assim, o momento histórico e social que se vive de policiar e judicializar as relações institucionais em nome de uma normalização dos desajustes postos, como forma de padronização de condutas.

Recebido em: 20/03/2018 e aprovado em: 19/07/2018

\section{Referências}

ARAÚJO, I. L. Foucault e a crítica do sujeito. Curitiba: ed. da UFPR, 2001.

FOUCAULT, M. Em defesa da sociedade. 3. ed. São Paulo: Martins Fontes, 2002. Tradução: Maria Ermantina Galvão

A ordem do discurso. 9. ed. São Paulo, SP: Edições Loyola, 2003. Tradução: Laura Fraga de Almeida Sampaio. 
NAVARRO-BARBOSA, P. L. O acontecimento discursivo e a construção da identidade histórica. In: SARGENTINI, V. \& NAVARRO-BARBOSA, P. L. (Org.). M. Foucault e os domínios da linguagem: Discurso, poder, subjetividade. São Carlos/SP: Claraluz, 2004.

PASSOS, I. C. F. Situando a analítica do poder em Michel Foucault. In: (Org.). Poder, normalização e violência: incursões foucaultianas para a atualidade. Belo Horizonte, MG: Autêntica Editora (Coleção Estudos Foucaultianos), 2008.

RATTO, A. L. S. Livros de ocorrência: (in)disciplina, normalização e subjetivação. São Paulo: Cortez, 1997. 